\title{
Topographical effects of climate data and their impacts on the estimation of net primary productivity in complex terrain: A case study in Wuling mountainous area, China
}

\author{
Sun Qing-ling a,b, Feng Xian-feng a,*, Ge Yong ${ }^{\mathrm{a}}$, Li Bao-lin ${ }^{\mathrm{a}}$ \\ a Institute of Geographic Sciences and Natural Resources Research, Chinese Academy of Sciences, Beijing 100101, China \\ b Graduate University of Chinese Academy of Sciences, Beijing 100049, China
}

\section{A R T I C L E I N F O}

\section{Article history:}

Received 6 November 2014

Received in revised form 6 January 2015

Accepted 17 February 2015

Available online 11 March 2015

\section{Keywords:}

Topographical effects

Climate data

NPP estimation

BEPS model

ANUSPLIN

\begin{abstract}
A B S T R A C T
Topography has remarkable effects on the local climate, especially in mountainous areas. The accuracy of climate data is pivotal to the estimation of net primary productivity (NPP). Unrealistic simulations of climate data without considering the topography would lead to biased estimation of NPP. In this work, we aim to evaluate quantitatively the NPP difference with and without considering the topographical effects of climate data, and furthermore, to explore the spatio-temporal characteristics of NPP difference and the primary contributing variables to the difference. For these purposes, two different climate datasets were first built and compared with the station observations, one of which considered topographical effects (terrain-based climate dataset) while the other one did not (ordinary climate dataset). We quantified topographical effects of climate data on NPP estimation by inputting two different climate datasets to the same ecosystem model, the Boreal Ecosystem Productivity Simulator (BEPS), to evaluate the importance of considering topography during NPP calculations. Then, spatiotemporal characteristics of the NPP difference were explored, and the primary contributing variables were determined through a series of simulation experiments. Results showed that, on average, ordinary climate dataset underestimated NPP by $12.5 \%$ compared with terrain-based climate dataset over the whole Wuling mountainous area. Topographical effects of climate data had larger impacts on the NPP estimation in summer time than in winter months. In space, differences between ordinary NPP and terrain-based NPP were negligible below $200 \mathrm{~m}$, and above $200 \mathrm{~m}$, the differences increased first and then steadily decreased; discrepancies between NPPs continually augmented with the slope increasing; and NPP was more likely to be affected in the north and northwest than in the south and southeast. The primary climate variables contributing to the NPP difference in Wuling mountainous area were temperatures, followed by global solar radiation. The research methods developed in this case study can also be applied to other study areas and other ecosystem models.
\end{abstract}

(c) 2015 Elsevier B.V. All rights reserved.

\section{Introduction}

The terrestrial carbon cycle is one of the core issues of global change research (Cramer and Field, 1999). Accurate estimation of net primary productivity (NPP) has been a subject of increasing interest because of the importance of NPP in global atmospheric $\mathrm{CO}_{2}$ budget affecting climate and terrestrial carbon cycle (Feng et al., 2004; Zhou and Wang, 2003). NPP is also the primary source of food for human beings and other living organisms (Running, 2012), and it provides information useful for the management of natural resources to achieve sustainable development (Liu et al., 1997).

In the light of difficulties to measure NPP directly in large spatial extents, a multitude of models have been developed for large-scale NPP estimations (Cramer et al., 1999). From earlier statistical models (Lieth,

\footnotetext{
* Corresponding author at: 11A Datun Road, Chaoyang District, Beijing, China. Tel.: + 86 1064889047.

E-mail address: fengxf@lreis.ac.cn (F. Xian-feng).
}

1972; Zhou and Zhang, 1995) to recent process-based models (Liu et al., 1999; Piao et al., 2012; Tian et al., 2010), estimating tools for NPP have combined more techniques (e.g. remote sensing) and their accuracies have been improving steadily (Xu et al., 2007; Zhu et al., 2005). As previous studies reported, there were large discrepancies among these model estimates even using the same model due to different model structure, quality of input variables, model parameterization, and calibration (Feng et al., 2007; Wang, 2004). Baldocchi et al. (2002) based on a modeling point of view, partitioned the uncertainties in modeling carbon and water fluxes within an ecosystem into five categories, and the accuracy of driving environmental variables is one of the critical sources. Further, authors concluded that better representation of $\mathrm{CO}_{2}$ and water vapor exchange between vegetation canopy and atmosphere would require more and better input data (Baldocchi et al., 2002).

Meteorological variables determining the environmental conditions for vegetation growth are major input data required by most ecosystem models. Their accuracies are pivotal to the estimation of 
NPP (Matsushita et al., 2004). Topography has remarkable effects on the simulation of climate data including temperature, precipitation, humidity, incident solar radiation, et al., especially in mountainous areas (Zhou et al., 2007). In previous studies, traditional methods such as bilinear interpolation or kriging interpolation have been utilized to acquire the spatial distribution of meteorological data in complex terrain (Li, 2013; Piao and Fang, 2002; Zheng, 2006), especially for the global solar radiation (Zhou et al., 2007). Such unrealistic simulations of climate data without considering the topographical effects would give rise to biases in estimated net $C$ exchange between the atmosphere and ecosystems. Chen et al. (2007) reported that, with consideration of topographical effects on the climate data, simulated NPP could account for $76 \%$ of the variability in measured NPP across all the sampled sites at the middle of Chinese Qinling Mountain, while excluding topographical effects the simulated values only captured $64 \%$ of the variability. Liu et al. (2013) compared NPP results simulated before and after topographical corrections of air temperature and total solar radiation in a mountainous region of central China, and concluded that without consideration of topographical effects, simulated mean NPP was significantly underestimated. At present, even though there are a few studies paying attention to the topographical effects on NPP estimation, they generally focus on the difference or deviation between NPPs with and without considering the topographical effects. Primary contributing variables to the NPP difference and its spatio-temporal characteristics in complex terrain are still not researched (Huang et al., 2010). It should be noted that, except local climate, topographical influences on NPP estimation can from various aspects, such as soil nutrient transformation (Ryunosuke et al., 2004) and lateral movement of soil water (Chen et al., 2007; Grant, 2004). But, in this paper only the topographical effects from climate data are evaluated and explored intensively for modeling NPP more accurately in complex terrain.

In this work, we aim to evaluate quantitatively the NPP difference with and without considering topographical effects of climatic inputs, and furthermore, to explore the spatio-temporal characteristics of NPP difference and contributions of various climate variables to the difference. For these purposes, we are going to: (1) build two different climate datasets with and without considering the topography during simulations of climate data, and then compare them with the station observations; (2) quantify the topographical effects of climatic inputs on NPP estimation by inputting two different climate datasets to the same process-based model, BEPS model; (3) analyze the spatio-temporal characteristics of the NPP difference resulted from different climatic inputs; and (4) design experiments to find the primary contributing variables to the difference given an overall accuracy of the model output for NPP.

\section{Materials and methods}

\subsection{Study area}

Wuling mountainous area $\left(25^{\circ} 52^{\prime}-31^{\circ} 24^{\prime} \mathrm{N}, 107^{\circ} 4^{\prime}-112^{\circ} 2^{\prime} \mathrm{E}\right)$ is a large region where Wuling Mountain is located. It lies in the southcentral China and spreads for $420 \mathrm{~km}$ across three provinces (i.e. Hubei Province, Hunan Province, Guizhou Province) and one municipality-Chongqing City (Fig. 1). The total area is approximately $171,800 \mathrm{~km}^{2}$ and the altitude ranges from -9 to $2979 \mathrm{~m}$ above sea level. Most of lands in the study area are hillsides with the mean slope of $15^{\circ}$. Soil erosion is severe and rocky desertification is widely developed in this region. Located in the ecotone from subtropical to warm temperate zone, mean annual temperature for Wuling mountainous area is $13.5-17.0^{\circ} \mathrm{C}$, and mean annual precipitation is from 1100 to $1600 \mathrm{~mm}$. Influenced by the climate and terrain, main soil types in the study area are yellow soil, red soil, and yellow-brown soil. Prevalent vegetation types are forests including evergreen broadleaf forest, evergreen coniferous forest, deciduous broadleaf forest, and mixed broadleaf-conifer forest. Wuling mountainous area has a very high percentage of forest cover and it is the core district of subtropical forests distributed in China. At the same time, however, it is also one of the vulnerable ecological regions and plays an important role in the environmental development of south China.

\subsection{Climate data}

Climate variables required by BEPS model include daily maximum temperature, minimum temperature, precipitation, relative humidity, and global solar radiation. Temperatures, precipitation, and relative humidity are conventional meteorological observations of intensive weather station network with 104 stations over Wuling mountainous area and its perimeter zone. Among them, there are 12 stations above $1000 \mathrm{~m}$ (only 2 stations in Wuling mountainous area) and 18 stations located in 500-1000 m. At the same time, 36 stations are situated below $200 \mathrm{~m}$ (Fig. 2). Traditional bilinear interpolation method of BEPS model, however, is not suitable for this situation because of the uneven distribution of meteorological stations in the vertical dimension. Thin plate spline interpolation algorithm (Hutchinson, 2001) was adopted in this study to acquire the spatial climate data for NPP estimation, and the interpolation software, ANUSPLIN 4.2, was applied to accomplishing this. As to incoming solar radiation, stations are so sparse (only 7 stations located in the interpolation area) that it cannot be

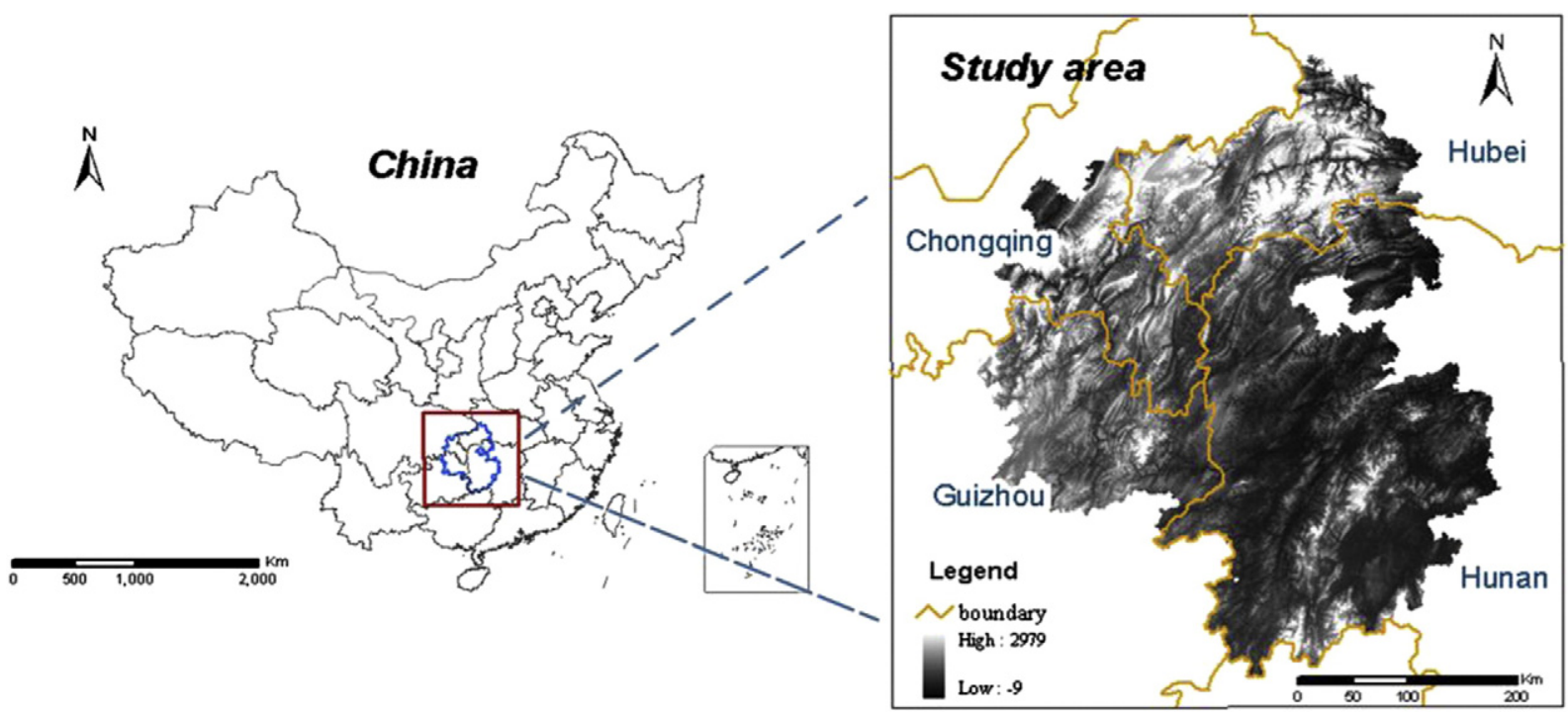

Fig. 1. Location and topography of the study area. 


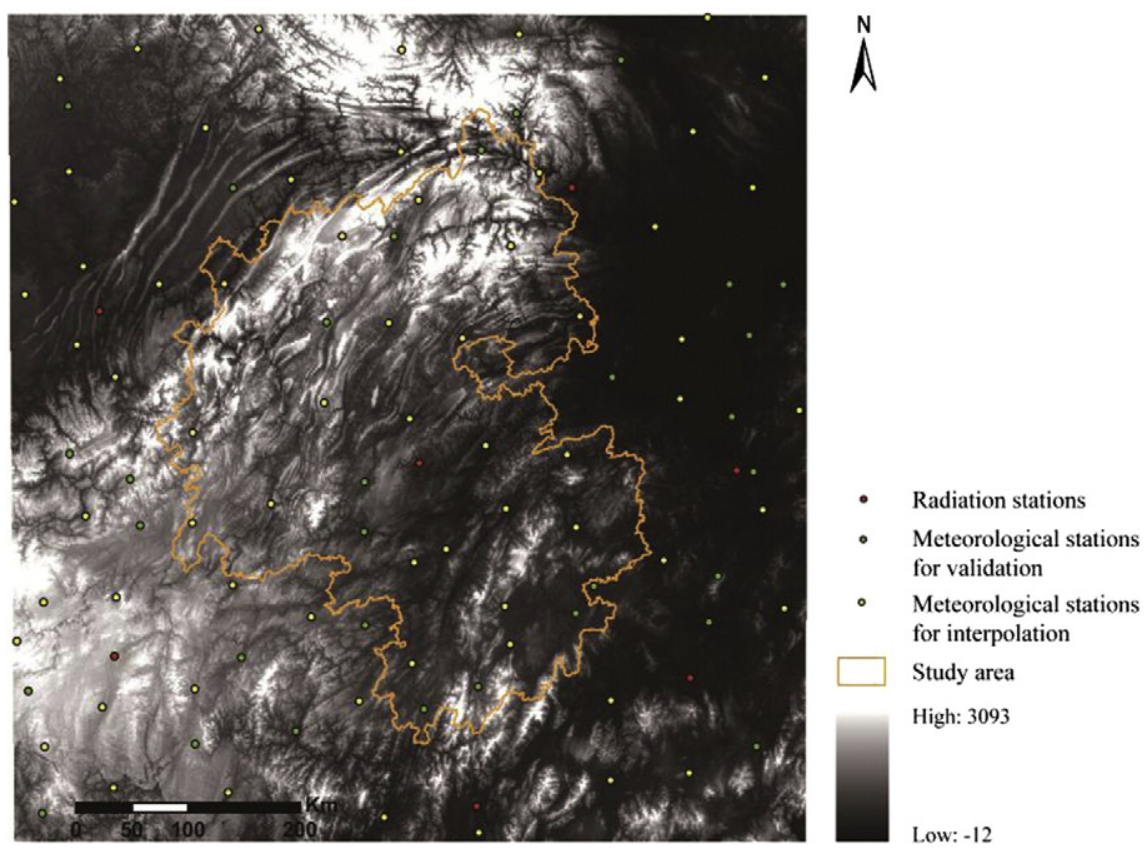

Fig. 2. Spatial distribution of meteorological stations used in the study.

directly obtained through interpolation. In this research, daily solar radiation was estimated using an empirical equation based on the spatially distributed sunshine duration (Angstrom, 1924; He and Xie, 2010) which was also acquired through interpolation using ANUSPLIN.

ANUSPLIN has been employed successfully at various regions and scales (Feng et al., 2007; Price et al., 2000). One of its greatest advantages is that it allows for including terrain factors influencing the climate variable as additional covariates during the interpolation. According to our previous study Sun et al. (2014) and Chen et al. (2007), elevation, slope, and aspect are main variables affecting the spatial distributions of temperatures and global solar radiation. So, we chose elevation, slope, and aspect as covariates during the interpolation of maximum temperature, minimum temperature, and sunshine duration, while the longitude and latitude were used as independent spline variables. In regard to precipitation and relative humidity, only the elevation was utilized as the covariate during interpolations. For comparison, similar operations based on the ANUSPLIN with only longitude and latitude data as the independent spline variables and without any terrain factor served as the covariate were executed.

Daily solar radiation $(S)$ was calculated using the following empirical equation:

$S=\left(a+b \times \frac{N}{N_{0}}\right) \times S_{0}$,

where $N$ is the sunshine duration, and $a$ and $b$ are the empirical constants which vary with the geographical locations. For Wuling mountainous area, $a$ and $b$ are assigned 0.0058 and 0.17 respectively according to our regression results $\left(R^{2}=0.79\right.$, RMSE $\left.=7.8 \%\right) . S_{0}$ is the extraterrestrial solar radiation, and its calculation formulas can be obtained from Weng (1997). $N_{0}$ is the maximum possible sunshine duration estimated from the latitude $(\varphi)$ and solar declination $(\delta)$ :

$\mathrm{N}_{0}=\frac{24}{\pi} \arccos (-\tan (\varphi) \tan (\delta))$.

Similarly, we obtained two different radiation inputs of the study area based on two sets of sunshine duration data which had been acquired through interpolations with ANUSPLIN. The climate data considering topography during interpolations formed the terrain-based climate dataset, while those climate data without including any terrain factor as the covariate in the interpolation processes made up the ordinary climate dataset.

\subsection{Model description}

BEPS model combines remote sensing and ecological process approaches to simulate spatially carbon and water fluxes between terrestrial ecosystems and the atmosphere. BEPS was built based on the stand-level model, FOREST-BGC (Running and Coughlan, 1988), but it extended stand-level calculations to larger areas (watershed, landscape, province, or a region) using gridded meteorological and soil data rather than single station data (Liu et al., 1999). Compared with the origin version of Forest-BGC, BEPS model is refined in many aspects: (1) BEPS model includes a canopy-scale photosynthesis model developed from Farquhar's leaf-scale biochemical model (Farguhar et al., 1980) using a spatial and temporal scale transformation (Chen et al., 2007); (2) it has a more advanced radiation transfer model introducing foliage clumping index to represent the effect of canopy architecture on radiation interception and absorption (Chen and Cihlar, 1995); and (3) BEPS provides a good framework to address the challenge of integrating data from different sources and making them spatially and temporally compatible (Liu et al., 1997). Detailed descriptions of the model structure and formulas can be found in Liu et al. $(1997,1999)$ and Chen et al. (1999).

BEPS has been utilized to estimate NPP at various scales in Canada (Liu et al., 1999; Liu et al., 2002), China (Chen et al., 2007; Feng et al., 2007), and Japan (Higuchi et al., 2005; Huang et al. 2010). The robustness has been repeatedly validated and confirmed (Xu et al., 2007). In this study, some adjustments have been made to the BEPS model to estimate NPP more accurately. The adjustments include: (1) initial values of some biophysical parameters are modified based on the vegetation type according to previous studies Tables 1 and 2 interpolation results based on the ANUSPLIN are directly inputted to the BEPS model and the algorithm for calculating daily global solar radiation is also embedded into the model. 
Table 1

Some biological parameters for major vegetation types required by BEPS model.

\begin{tabular}{|c|c|c|c|c|c|c|c|}
\hline Parameters & Unit & $\begin{array}{l}\text { Broadleaf } \\
\text { forest }\end{array}$ & $\begin{array}{l}\text { Coniferous } \\
\text { forest }\end{array}$ & $\begin{array}{l}\text { Mixed } \\
\text { forest }\end{array}$ & Shrub & Pasture/Crop & Reference \\
\hline Specific leaf area & $\mathrm{m}^{2} \mathrm{~kg} \mathrm{C}^{-1}$ & 20 & 25 & 20 & 10 & 30 & Feng et al. (2007) \\
\hline Clumping index & - & 0.7 & 0.5 & 0.6 & 0.6 & 0.9 & Feng et al. (2007) \\
\hline Max. stomatal conductance & $\mathrm{m} \mathrm{s}^{-1}$ & 0.0045 & 0.0022 & 0.0025 & 0.004 & 0.005 & Matsushita and Tamura (2002) and Feng et al. (2007) \\
\hline Leaf respiration coefficient & $\mathrm{kgC} \mathrm{d}^{-1} \mathrm{~kg}^{-1}$ & 0.00398 & 0.00267 & 0.003 & 0.006 & 0.002 & Xu et al. (2007) and Matsushita et al. (2004) \\
\hline Stem respiration coefficient & $\mathrm{kgC} \mathrm{d}^{-1} \mathrm{~kg}^{-1}$ & 0.00005 & 0.00005 & 0.00005 & 0.00005 & 0.00005 & Xu et al. (2007) and Matsushita et al. (2004) \\
\hline Root respiration coefficient & $\mathrm{kgC} \mathrm{d}^{-1} \mathrm{~kg}^{-1}$ & 0.0002 & 0.0002 & 0.0002 & 0.0002 & 0.0002 & Xu et al. (2007) and Matsushita et al. (2004) \\
\hline
\end{tabular}

\subsection{Data acquisition and processing}

The required BEPS input data, including land cover, LAI, AWC, soil water content, DEM, forest biomass, and meteorological data, were all processed in the same coordinate system (Krassovsky ellipsoid/Albers conical equal area projection) with a spatial resolution of $500 \mathrm{~m}$.

\subsubsection{Land cover}

Land cover data is mainly used to determine biophysical parameters that are dependent on the vegetation types. The land cover map of Wuling mountainous area is part of a 2010 nationwide land cover map (30 m resolution, interpreted from 16 Landsat TM images) with more than 30 classes originally. In this study, we regrouped the land cover types into 13 categories according to Feng et al. (2007), then the map was resampled at $500 \mathrm{~m} \times 500 \mathrm{~m}$ using the Majority method provided in the ArcGIS resample tool. The final land cover map at a spatial resolution of $500 \mathrm{~m}$ is shown in Fig. 3.

\subsection{2. $L A I$}

A consistent 8-day composite LAI series in 2010 generated from MODIS data based on the GLOBCARBON algorithm (Deng et al., 2006) at the resolution of $500 \mathrm{~m}$ was used to drive BEPS model in this work. The GLOBCARBON algorithm is a physical LAI retrieval method which was developed on the basis of a geometrical optical model (4-Scale) and embedded BRDF corrections during its reversal processes. Derived LAI compared favorably against the field plot measurements and fine resolution LAI maps at the national scale (Liu et al., 2012). The LAI data of our study area was derived from extraction with the usage of boundary vector of Wuling mountainous area.

\subsubsection{Soil data}

Available soil water is a crucial factor affecting plant growth. The AWC data was derived from Harmonized World Soil Database (HWSD, version 1.2) which was compiled using the European Soil Database (ESDB), the 1:1 million soil map of China, various regional SOTER (the SOil and TERrain) databases, and the Soil Map of the World (Nachtergaele et al., 2012). The 1:1 million soil data of China is provided by Nanjing Institute of Geography \& Limnology, Chinese Academy of Sciences, and the data comes from a large number of samples in the field. In this database, 7 AWC classes had been estimated for all soil units accounting for topsoil $(0-30 \mathrm{~cm})$ textural class and depth/volume limiting soil phases. Codes and true values of the AWC data are shown in Table 2.

\subsubsection{Daily meteorological data}

Daily meteorological observation data including maximum temperature, minimum temperature, precipitation, relative humidity, sunshine duration, and solar radiation in 2010 is available from China Meteorological Data Sharing Service System (http://cdc.cma. gov.cn/home.do). According to methods described in the 1.3 , we first acquired two datasets of conventional meteorological variables using ANUSPLIN based on data of 69 stations which were randomly and uniformly selected from the 104 conventional meteorological stations (approximately 2/3) within our interpolation area (Fig. 2). Because of the particularity of incoming shortwave radiation, it was estimated using Eq. (2) separately. Then, we extracted values of the remaining 35 stations from two interpolated datasets and daily observation datasets involving temperatures, precipitation, and relative humidity. Regarding the solar radiation, observed data of 7 stations were all used to examine the accuracies and topographical effects of radiation inputs. Finally, comparisons were implemented both spatially and temporally.

\subsubsection{Forest biomass data}

Forest biomass is a critical input parameter for calculating autotrophic respiration of forest types. We produced this data mainly through linear relationships between aboveground biomass (AGB) and LAI (Feng et al., 2007; Zhou et al., 2007), as shown in Eq. (4):

$A G B=A \times L A I+B$

where $A$ and $B$ are cover-type dependent parameters, and the unit of AGB is $\mathrm{t} / \mathrm{hm}^{2}$. The aboveground biomass data was calculated from the dataset of Luo (1996), but we only used those sites where the vegetation type had not been changed compared with the land cover in 2010. The underground biomass was estimated through correlation with the aboveground biomass, and the ratio was given 1:4 in this study (Guo et al., 2002). After validation against ground data (also from Luo's dataset), total forest biomass for Wuling mountainous area was obtained.

\subsection{Simulation experiments}

A series of experiments were conducted to quantify what difference the distinct climatic inputs make to estimate NPP of Wuling mountainous area. Two climate datasets were used in the simulations, one of which considered topographical effects during interpolation processes was referred as terrain-based climate dataset, while the other one was called ordinary climate dataset. Climate variables were divided into 4 groups: (1) temperatures including maximum temperature and minimum temperature, (2) precipitation, (3) relative humidity, and (4) solar radiation. We first used all the variables from terrain-based climate dataset as input data to the BEPS model, which we called the baseline run. Then, we employed all the variables in the ordinary climate dataset to drive BEPS model again for a direct comparison. And next, we ran the model repeatedly, on the basis of the baseline run, by replacing one group of variables from the terrain-based climate dataset each time with the same group of variables from the ordinary climate dataset, to explore in depth the primary variables contributing to the 


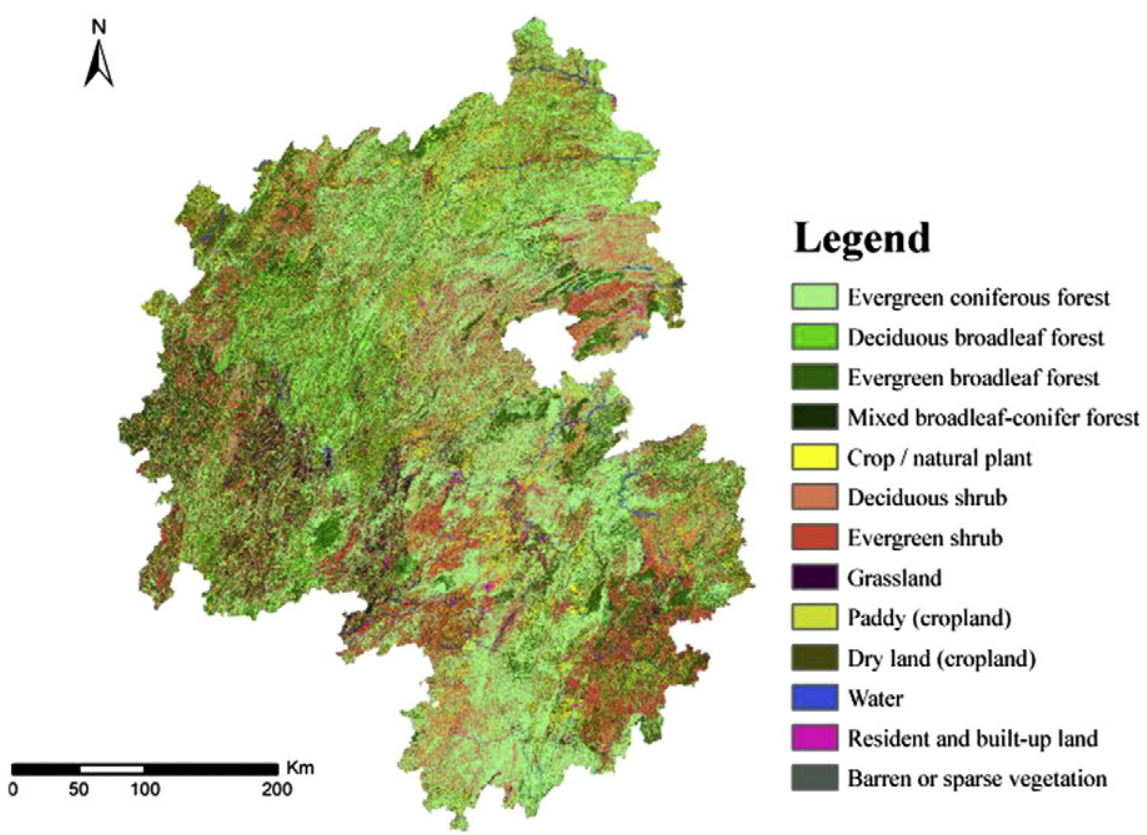

Fig. 3. Land cover map of Wuling mountainous area in 2010.

NPP difference with and without considering the topographical effects of climate data. Detailed design of simulation experiments is shown in Table 3.

\subsection{Spatio-temporal analysis of NPP difference}

In this study, simulated NPP acquired using all the terrain-based climate data was referred to as terrain-based NPP, while the NPP estimated based on all the ordinary climate data was referred to as ordinary NPP. The spatial distribution of NPP difference was calculated through terrain-based NPP minus ordinary NPP pixel by pixel. To further reveal the spatial pattern of NPP difference varying with the altitude, slope, and aspect, we divided the continuous altitude, slope, and aspect data into several intervals first. Then, we calculated mean value and standard deviation of two NPP estimations and their NPP difference within each interval. Finally, we used line charts to visualize the spatial variation characteristics of the NPP difference. The temporal variation characteristics of NPP difference was studied at monthly scale. The monthly NPP was obtained by modifying the output step of BEPS model to one month.

Table 3

Simulation experiments using two different climate datasets

\begin{tabular}{lllll}
\hline Simulations & Temperatures & Precipitation & Relative humidity & Solar radiation \\
\hline Experiment I & $*$ & $*$ & $*$ & $*$ \\
Experiment II & $*$ & $*$ & $*$ & $*$ \\
Experiment III & $*$ & $*$ & $*$ & $*$ \\
Experiment IV & $*$ & $*$ & $*$ & $*$ \\
Experiment V & $*$ & $*$ & $*$ & $*$ \\
Experiment VI & $*$ & $*$ & $*$ & $*$
\end{tabular}

Symbol * indicates the group of variables from terrain-based climate dataset, while the group of variables from ordinary climate dataset is indicated by symbol $\bullet$.

\section{Results}

\subsection{Comparison and validation of two climate datasets}

Two different climate datasets that comprised 5 variables in each of them were compared spatially and temporally. In terms of spatial patterns, terrain-based climate dataset presented more reliable topographical information and the simulated values revealed more accurate elevation gradients (Fig. $4 a-j$ ). Besides, the maximum value of each climate variable in the ordinary climate dataset was lower, while the minimum value was higher, than that of the corresponding terrainbased climate variable. Differences could only be explained by the topographical effects since other conditions were all the same, except whether we had introduced terrain factors as covariates or not during the interpolation processes.

Comparison and validation of two climate datasets with the station observation dataset were implemented on the daily scale during 365 days in 2010. From Table 4, it can be concluded that, terrain-based climate dataset was closer to the station observation dataset compared with the ordinary climate dataset. On average, without considering topographical effects, the daily maximum temperature was underestimated about $1.3^{\circ} \mathrm{C}$ and the daily minimum temperature was underestimated about $1.6^{\circ} \mathrm{C}$. For the daily precipitation and relative humidity, topographical effects were not so distinct. Compared with station observations, maximum difference of terrain-based solar radiation was $6090.14 \mathrm{KJ} \mathrm{m}^{-2} \mathrm{~d}^{-1}$, while the maximum difference of ordinary solar radiation reached $7357.83 \mathrm{KJ} \mathrm{m}^{-2} \mathrm{~d}^{-1}$. The correlation coefficients of simulated data and observation data were all very high, but the terrain-based climate data had higher correlation with the station observations in terms of all the climate variables. In addition, from the sign of differences, we concluded that simulated temperatures, precipitation, and relative humidity including both terrain-based data and ordinary data were all smaller than the actual observations. However, as for global solar radiation, this study seemed to overestimate it in some degree.

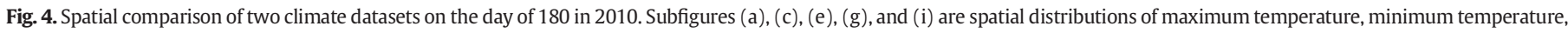

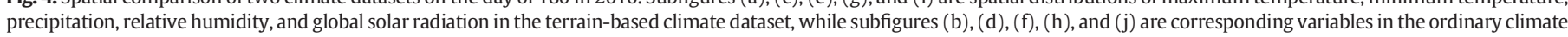
dataset. 


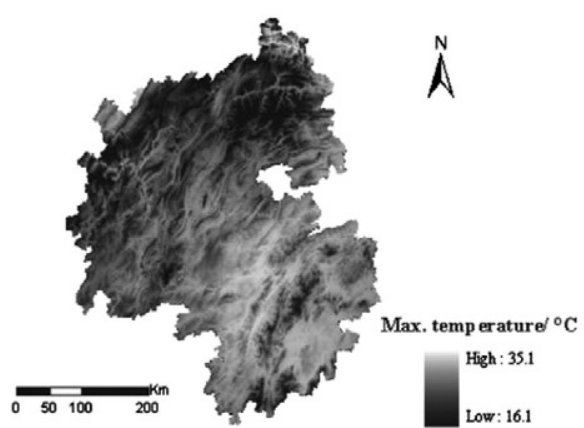

a

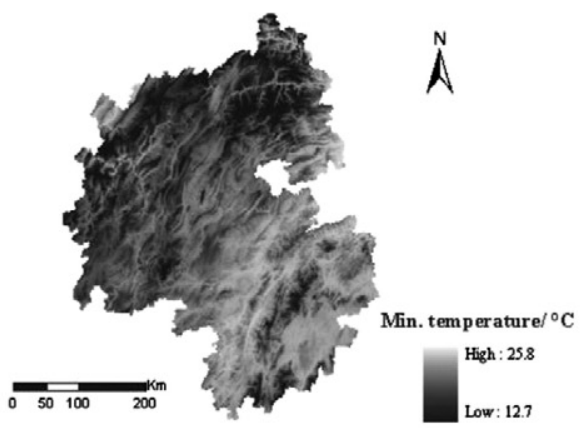

c

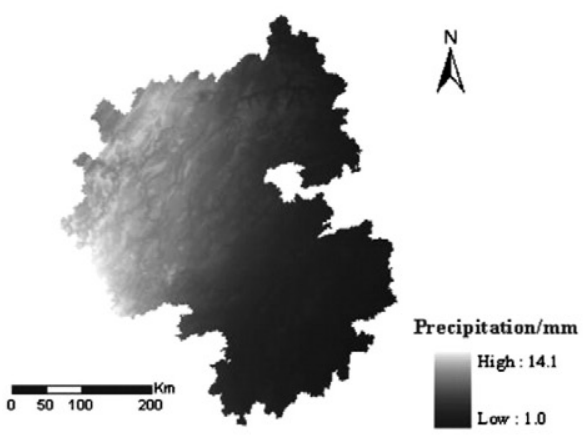

e

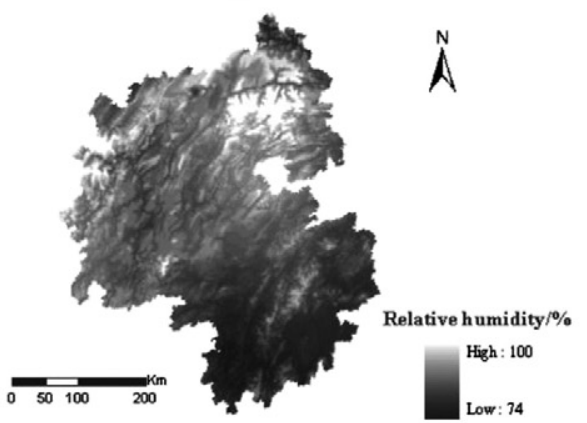

$\mathrm{g}$

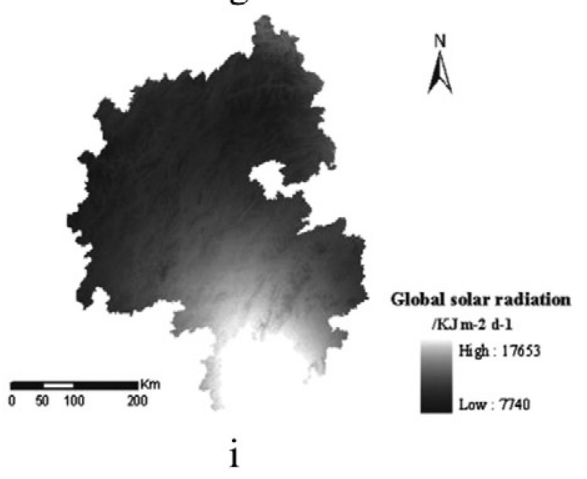

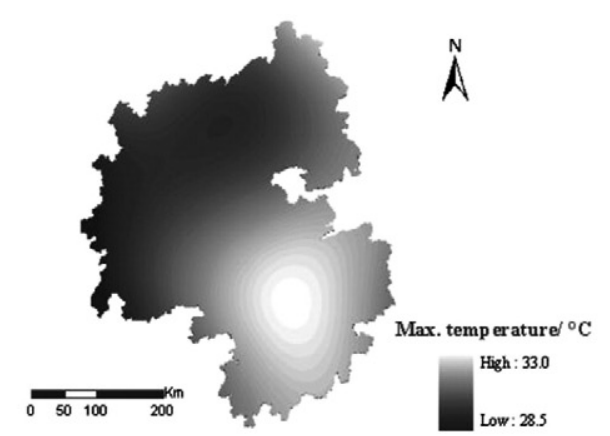

b

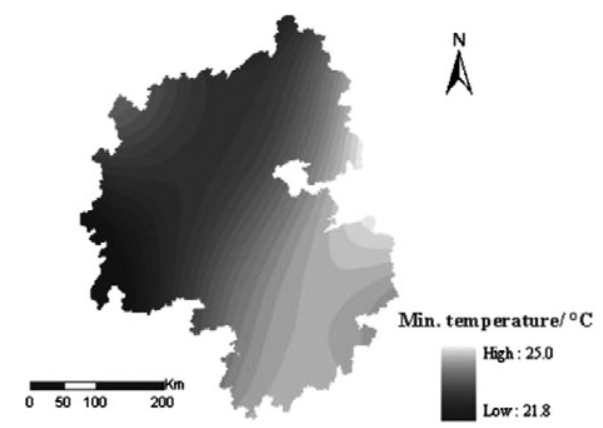

d

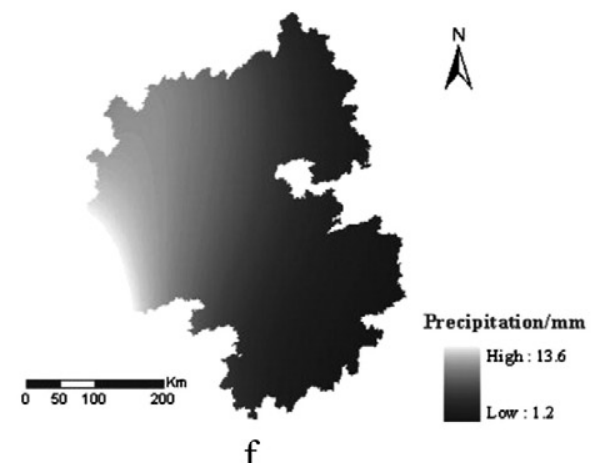

$\mathrm{f}$

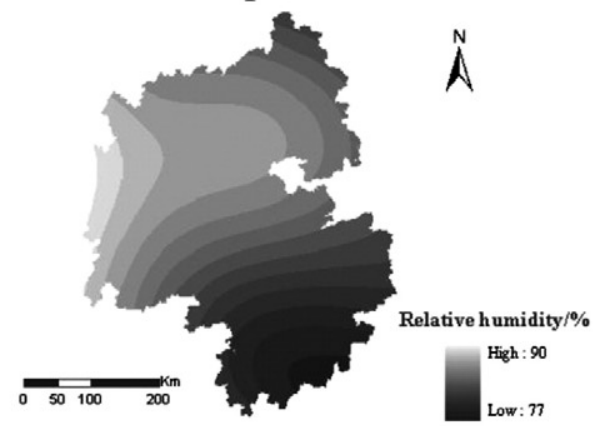

h

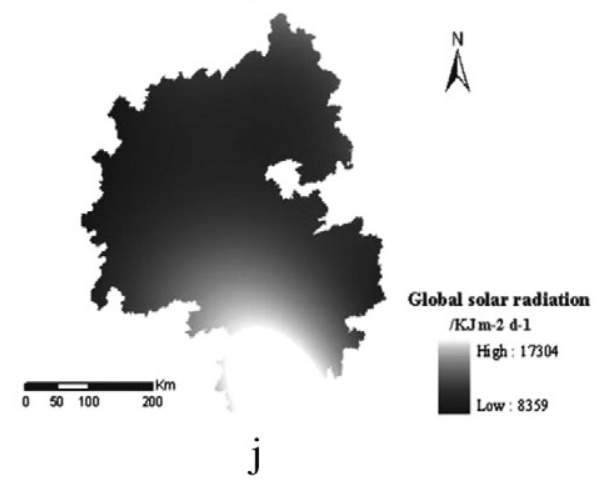


Table 4

Comparison and validation of simulated climate datasets with the station dataset during 365 days in 2010.

\begin{tabular}{|c|c|c|c|c|c|}
\hline Climate datasets & Climate variables & Maximum differences & Minimum differences & Mean differences & Correlation coefficients \\
\hline \multirow[t]{5}{*}{ Terrain-based } & Maximum temperature $\left({ }^{\circ} \mathrm{C}\right)$ & -3.47 & 0 & -0.82 & 0.995 \\
\hline & Minimum temperature $\left({ }^{\circ} \mathrm{C}\right)$ & -1.87 & 0 & -0.44 & 0.998 \\
\hline & Precipitation (mm) & -17.95 & 0 & -1.39 & 0.915 \\
\hline & Relative humidity (\%) & -8.38 & 0 & -2.00 & 0.945 \\
\hline & Solar radiation $\left(\mathrm{KJ} \mathrm{m}^{-2} \mathrm{~d}^{-1}\right)$ & 6090.14 & 20.86 & 2058.63 & 0.886 \\
\hline \multirow[t]{5}{*}{ Ordinary } & Maximum temperature $\left({ }^{\circ} \mathrm{C}\right)$ & -4.99 & 0.02 & -2.07 & 0.993 \\
\hline & Minimum temperature $\left({ }^{\circ} \mathrm{C}\right)$ & -3.74 & 0.07 & -2.01 & 0.997 \\
\hline & Precipitation (mm) & -16.55 & 0 & -1.51 & 0.891 \\
\hline & Relative humidity (\%) & -8.69 & 0.01 & -2.05 & 0.940 \\
\hline & Solar radiation $\left(\mathrm{KJ} \mathrm{m}^{-2} \mathrm{~d}^{-1}\right)$ & 7357.83 & 42.65 & 3227.81 & 0.858 \\
\hline
\end{tabular}

\subsection{Topographical effects of climatic inputs on NPP estimation}

By inputting two different climate datasets to our BEPS model (experiment I and experiment II), topographical effects of climatic inputs on NPP estimation were quantified. From Fig. 5, spatial patterns of terrain-based NPP and ordinary NPP were almost identical on the whole, and distributions of high values and low values were also very similar. However, terrain-based NPP obviously had higher values than the ordinary NPP in most regions within Wuling mountainous area. The maximum value of terrain-based NPP in the study area was $1625 \mathrm{~g} \mathrm{C} \mathrm{m}^{-2} \mathrm{yr}^{-1}$, while the maximum ordinary NPP was only $1490 \mathrm{~g} \mathrm{C} \mathrm{m}^{-2} \mathrm{yr}^{-1}$ (Table 5). The mean values for the whole study area of terrain-based NPP and ordinary NPP were $555.17 \mathrm{~g} \mathrm{C} \mathrm{m}^{-2} \mathrm{yr}^{-1}$ and $485.50 \mathrm{~g} \mathrm{C} \mathrm{m}^{-2} \mathrm{yr}^{-1}$, respectively. The relative difference was $-12.5 \%$ (negative sign means NPP was underestimated by the ordinary climate dataset), and this difference was attributed to the topographical effects of climatic inputs on NPP estimation. For Wuling mountainous area, underestimated total NPP by the ordinary climate dataset reached $11.65 \mathrm{Tg}$ C.

\subsection{Spatio-temporal characteristics of the NPP difference}

From the maps of difference between terrain-based NPP and ordinary NPP (Fig. 6), we can see clearly that, on the whole, terrain-based NPP was higher than ordinary NPP in most regions of Wuling mountainous area. Lands with the terrain-based NPP lower than the ordinary NPP were mostly distributed in valleys. Terrain-based NPP and ordinary NPP were roughly the same (difference was within $10 \mathrm{~g} \mathrm{C} \mathrm{m}^{-2} \mathrm{yr}^{-1}$ ) in flat areas, such as the Dongting Lake Plain situated in the southeast of Wuling mountainous area. The relative NPP differences in these low regions were very small, basically within $\pm 5 \%$ in this study. Areas with larger positive difference were almost hills and mountains, and the difference of NPP in some high grounds within the study area could reach $500 \mathrm{~g} \mathrm{C} \mathrm{m}^{-2} \mathrm{yr}^{-1}$.

To explore detailed spatial characteristics of the NPP difference, mean NPP and NPP standard deviation within each altitude, slope, and aspect interval in our study area were analyzed. From Fig. 7a, it was observed that NPP difference was negligible below $200 \mathrm{~m}$. The mean value of NPP difference below $100 \mathrm{~m}$ was negative which indicated that the terrain-based NPP was smaller than the ordinary NPP on average. With the altitude increasing, NPP difference also increased until it reached the maximum of $195.68 \mathrm{~g} \mathrm{C} \mathrm{m}^{-2} \mathrm{yr}^{-1}$ in the interval of $1800 \mathrm{~m}$ to $2000 \mathrm{~m}$. Since then, the discrepancy of mean NPP steadily decreased. The smallest standard deviation of NPP difference occurred in the 100-200 m, while the largest dispersion of NPP difference was in the $2200-2500 \mathrm{~m}$. Slope seemed to have simpler impacts on the NPP calculations, since the mean value and standard deviation of NPP difference all continually augmented with the slope increasing, yet the rates of increment were gradually reduced. The maximum mean NPP for two NPP estimations both occurred in the slope interval of $35^{\circ}$ to $40^{\circ}$, but the difference between them was not the maximum (Fig. $7 \mathrm{~b}$ ).
As to the aspect, NPP was more likely to be affected in the north and northwest than in the south and southeast. The maximum NPP difference was in the northwest with an absolute difference of $82.21 \mathrm{~g} \mathrm{C} \mathrm{m}^{-2} \mathrm{yr}^{-1}$, while the minimum distinction, about $60 \mathrm{~g} \mathrm{C} \mathrm{m}^{-2} \mathrm{yr}^{-1}$, was observed in the southeast of our study area (Fig. 7c).

In Fig. 7d, it was obvious that differences between terrain-based NPP and ordinary NPP changed greatly on the monthly scale. From January to March, ordinary mean NPP was slightly higher than the terrain-based mean NPP, and the difference was no more than $5 \mathrm{~g} \mathrm{C} \mathrm{m}^{-2} \mathrm{yr}^{-1}$. Mean values of terrain-based NPP and ordinary NPP in April were almost the same, and the standard deviation of NPP difference was the lowest within the year. From May to October, monthly mean values of ordinary NPP were lower than those of terrain-based NPP with the maximum difference of $21.82 \mathrm{~g} \mathrm{C} \mathrm{m}^{-2} \mathrm{yr}^{-1}$ in August. Commencing from November, ordinary NPP was slightly higher than terrain-based NPP again. It was obvious that in our study area topographical effects of climatic inputs had larger impacts on the NPP estimation in summer time than in winter months, and the impacts in winter were so small that could be ignored in most cases.

\subsection{Primary climate variables contributing to the NPP difference}

Detailed results of experiment I to experiment VI are listed in the Table 6. On average, NPP estimated from ordinary climate dataset was $12.5 \%$ lower than that from terrain-based climate dataset with variations among different vegetation types, and the largest variation was for evergreen broadleaf forest ( $-19.7 \%)$. To explore in depth the primary climate variables contributing to the discrepancy, we examined the difference between terrain-based NPP and ordinary NPP for each climate variable, and found that the ordinary temperatures alone underestimated NPP by $10.9 \%$ over the study area in comparison with the baseline run, followed by ordinary global solar radiation $(-1.8 \%)$. Surprisingly, differences were negligible when using the ordinary precipitation and relative humidity data as the model inputs $(0.1 \%$ and $-0.4 \%$, respectively). These all indicated that the primary climate variables contributing to the topographical effects of climatic inputs for Wuling mountainous area were temperatures, followed by solar radiation. As to the precipitation and relative humidity, including topographical effects or not did not change the NPP results much. This is mainly due to the abundance of rain in our study area and the differences of precipitation and humidity were not enough to cause variation of NPP. However, on the other hand, differences of temperatures between the hilltop and the foot (or the sunny slope and shady slope) were significant, which were able to bring about variation of NPP sufficiently. Besides, from the Table 6 , we found the amplitude of underestimation using all the climate variables from ordinary climate dataset ( Difference $_{1}$ ) was smaller than the sum of Difference ${ }_{2}$ to Difference $_{5}$ obtained through using one variable from the ordinary climate dataset and the rest from terrain-based climate dataset, suggesting non-linear interactions among climate variables in the BEPS model to estimate NPP. 


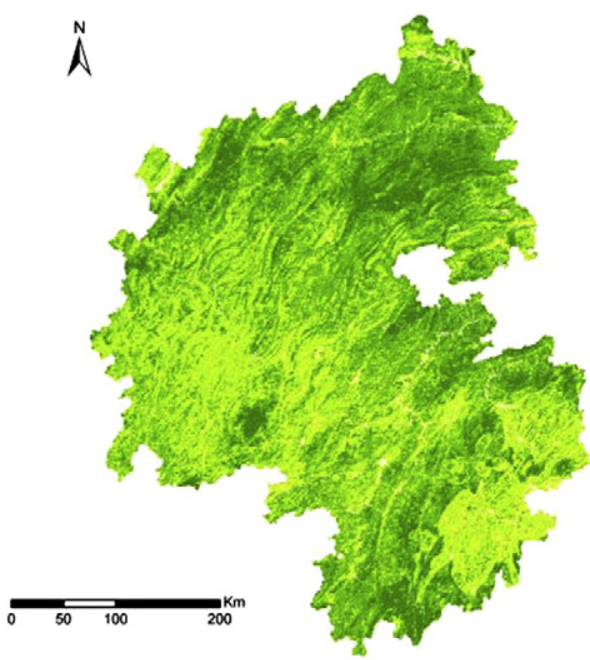

a

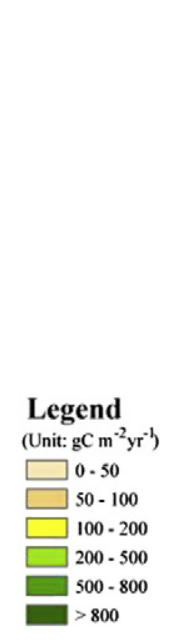

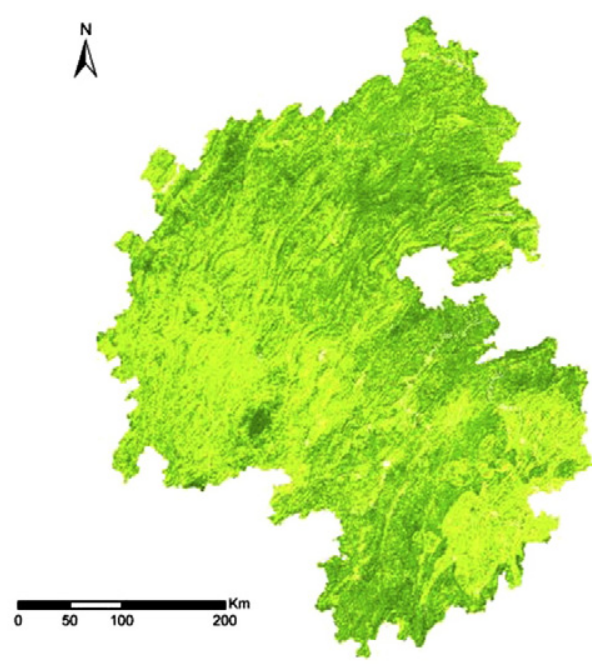

$\mathrm{b}$

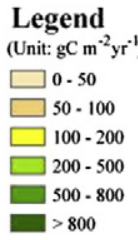

(1)

Fig. 5. Spatial distribution of terrain-based NPP (a) and ordinary NPP (b) in Wuling mountainous area in 2010.

\section{Discussion}

Chen et al. (2007) indicated that spatial variations of climate variables and lateral movement of soil water are the two main characteristics of mountainous areas. In some regions, especially in dry regions, exclusion of topographical effects on the lateral movement of soil water is expected to induce large uncertainties in the simulated NPP. However, the effect of lateral water flow is very small in Wuling mountainous area because this region generally has sufficient rainfall (Chen et al., 2007). This is advantageous for our study to focus on the topographical effects on the spatial variations of climate data. In addition, vegetation heterogeneity is also an important feature in complex terrain (Chen et al., 1999), and many biophysical parameters for NPP modeling vary with the vegetation types. Hence, accurate land cover data is required to achieve satisfactory modeling results. In our simulations, the land cover data used has a spatial resolution of $30 \mathrm{~m}$ with 30 classes originally. It is a part of results during the second national land survey in China, and we believe it has the best agreement with field surveys in the study area among all the available data at present.

In space, by dividing the continuous altitude, slope, and aspect data into several intervals, we explored the spatial characteristics of NPP difference caused by topographical effects of climate data in Wuling mountainous area. According to the results (Fig. 7a-c), variation tendencies of two NPP estimations as well as the NPP difference are very similar in space. This reflects that although exclusion of topographical effects of climate data can lead to inaccurate estimation of NPP, it does not influence the variation pattern in space on the whole. In Fig. 7d, we can see that, compared with terrain-based NPP, ordinary NPP slightly overestimated the NPP in winter months, while it greatly underestimated the NPP in summer time. This inconformity is caused by the biased simulations of climate data. In Fig. 4, it can be clearly observed that the maximum value of each climate variable in the ordinary climate dataset is lower, while the minimum value is higher than that of the corresponding terrain-based climate data. On the monthly scale, by calculating mean values of temperatures, precipitation, relative humidity, and total solar radiation of two climate datasets, we find that the mean values of ordinary climate dataset are generally lower than those of terrain-based climate dataset in the summer time, while this relationship is opposite in the winter months, especially for temperatures. We think it can explain the temporal variation pattern of NPP difference to some extent.

In this study, we concluded that the primary climate variables contributing to the NPP difference in Wuling mountainous area were temperatures, followed by global solar radiation. It should be noted that the primary contributing variables are study area dependent. In Wuling mountainous area, the rainfall is plentiful, so precipitation and humidity are not the main factors impacting the variation of NPP. On the contrary, because of frequent mist and large elevation range in the study area, incoming solar radiation and temperatures become the primary contributing variables to the variation of NPP. Finally, in our study area, due to lack of flux data to validate the NPP estimations, we took terrainbased NPP as the reference, and concluded that the relative difference was $-12.5 \%$. However, terrain-based NPP is not actually the true NPP. According to Chen et al. (2007) and Table 4, it may also underestimate the true NPP in some degree; therefore, the relative difference of NPP is very likely greater than $12.5 \%$ without considering topographical effects during simulations of climate data for Wuling mountainous area.

\section{Conclusions}

The quality and accuracy of the input climate data to ecosystem models are pivotal to the model outputs, such as NPP. To evaluate the importance of considering topographical effects of climatic inputs on NPP calculations and further to explore the spatio-temporal characteristics of NPP difference, we built two climate datasets first (terrain-based climate dataset and ordinary climate dataset) in Wuling mountainous area for case study. Then, we quantified the topographical effects of climatic inputs on NPP estimation by inputting two different climate datasets to the same BEPS model. Based on those, spatio-temporal

Table 5

Comparison of quantitative characteristics between two NPPs.

\begin{tabular}{|c|c|c|c|c|c|}
\hline NPP data & Mean NPP $\left(\mathrm{g} \mathrm{C} \mathrm{m}^{-2} \mathrm{yr}^{-1}\right)$ & Total NPP (Tg C) & Maximum NPP $\left(\mathrm{gC} \mathrm{m}^{-2} \mathrm{yr}^{-1}\right)$ & Minimum NPP $\left(\mathrm{g} \mathrm{C} \mathrm{m}^{-2} \mathrm{yr}^{-1}\right)$ & NPP Standard deviation $\left(\mathrm{g} \mathrm{C} \mathrm{m}^{-2} \mathrm{yr}^{-1}\right)$ \\
\hline Terrain-based NPP & 555.17 & 92.96 & 1625 & 0 & 243.58 \\
\hline Ordinary NPP & 485.50 & 81.29 & 1490 & 0 & 206.65 \\
\hline
\end{tabular}



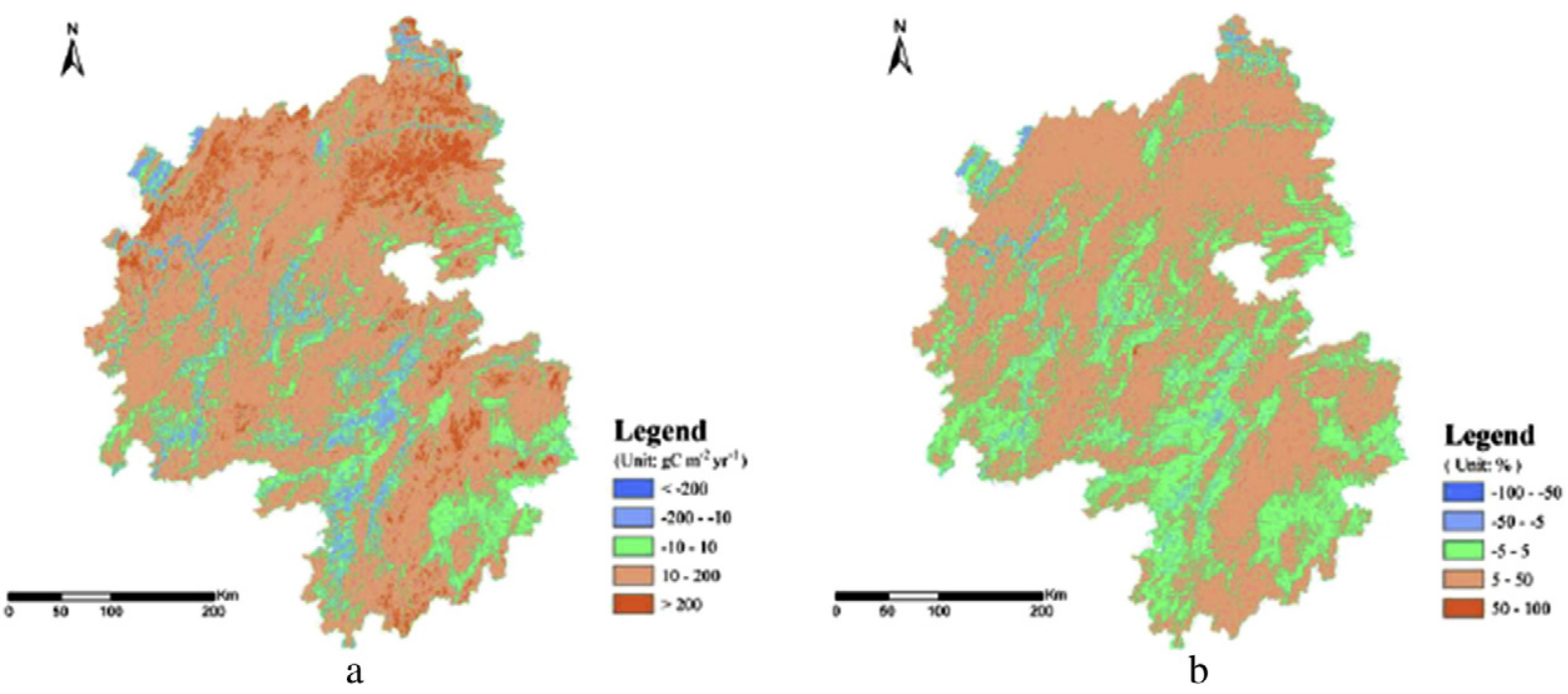

Fig. 6. Map of difference (a) and relative difference (b) of NPP in Wuling mountainous area.

characteristics of the difference between two NPP estimations were analyzed. Finally, primary contributing variables to the NPP difference were determined through a series of simulation experiments. The main conclusions are as follows:

(1) Terrain-based climate dataset presents more reliable topographical information and has closer agreements with the station observations compared with ordinary climate dataset on the daily scale.

(2) Annual mean values in 2010 for the whole study area of terrainbased NPP and ordinary NPP are $555.17 \mathrm{~g} \mathrm{C} \mathrm{m}^{-2} \mathrm{yr}^{-1}$ and
$485.50 \mathrm{~g} \mathrm{C} \mathrm{m}^{-2} \mathrm{yr}^{-1}$, respectively. On average, ordinary climate dataset underestimates the mean NPP by $12.5 \%$ compared with terrain-based climate dataset over the whole study area.

(3) Differences between terrain-based NPP and ordinary NPP change greatly on the monthly scale. Topographical effects of climatic inputs have larger impacts on the NPP estimation in summer time than in winter months. In space, differences between ordinary NPP and terrain-based NPP are negligible below $200 \mathrm{~m}$, but with the altitude increasing, NPP distinction also increases until it reaches the maximum in the interval of $1800-2000 \mathrm{~m}$. However, a

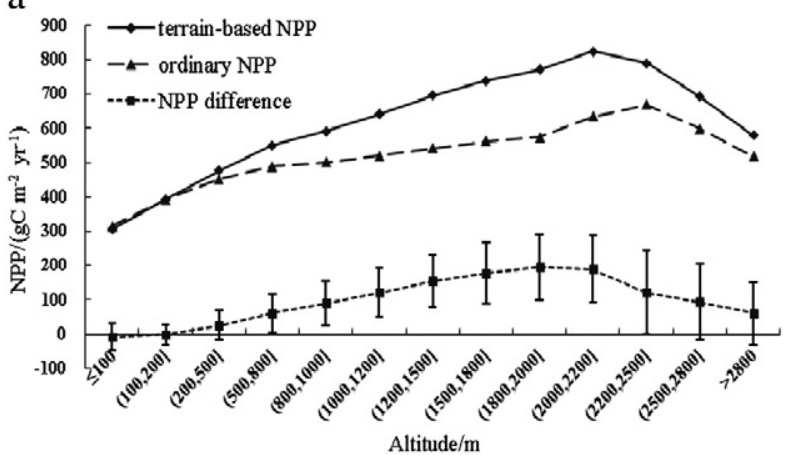

C

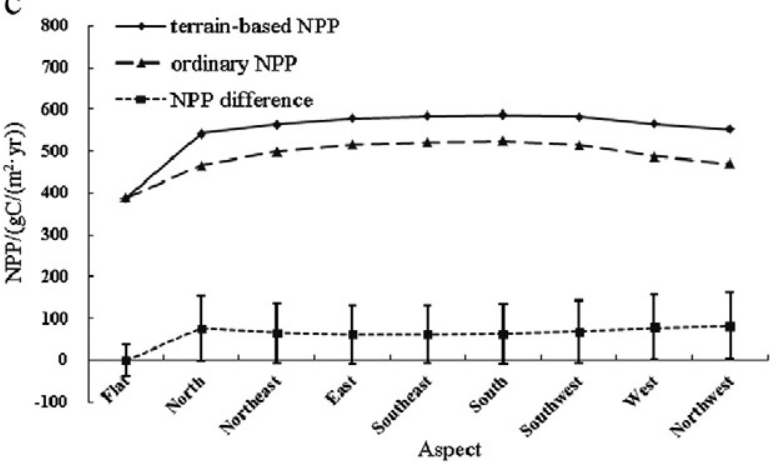

b

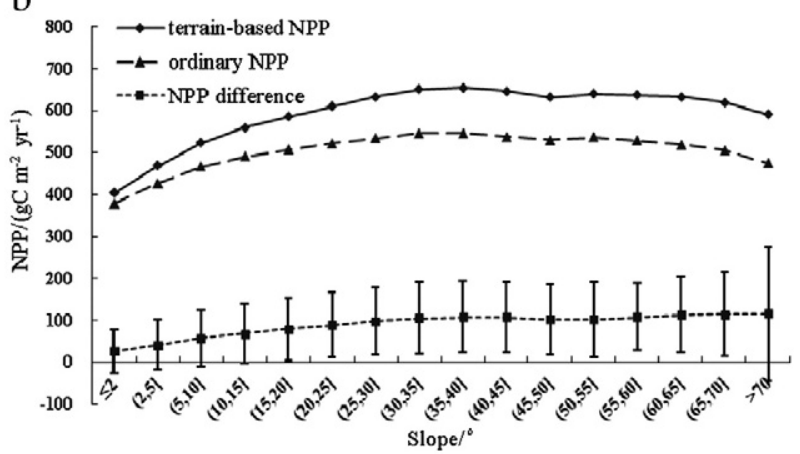

d

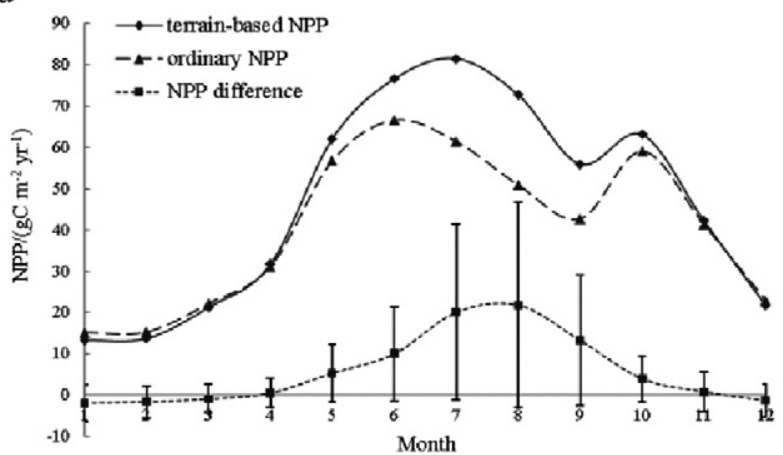

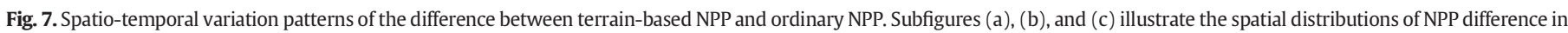
terms of altitude, slope, and aspect, respectively. The subfigure (d) indicates the temporal variation of NPP difference. 
Table 6

Contributions of different climate variables to the NPP difference for various vegetation types.

\begin{tabular}{|c|c|c|c|c|c|c|}
\hline Vegetation types & $\mathrm{NPP}_{0}$ & $\mathrm{NPP}_{1}$ (Difference $_{1}$ ) & $\mathrm{NPP}_{2}$ (Difference $)_{2}$ & $\mathrm{NPP}_{3}$ (Difference ${ }_{3}$ ) & $\mathrm{NPP}_{4}$ (Difference 4 ) & $\mathrm{NPP}_{5}\left(\right.$ Difference $\left._{5}\right)$ \\
\hline Evergreen coniferous forest & 555.89 & $\begin{array}{l}466.72 \\
(-16.0 \%)\end{array}$ & $\begin{array}{l}475.61 \\
(-16.0 \%)\end{array}$ & $\begin{array}{l}556.10 \\
(0)\end{array}$ & $\begin{array}{l}554.66 \\
(-0.2 \%)\end{array}$ & $\begin{array}{l}548.80 \\
(-1.3 \%)\end{array}$ \\
\hline Deciduous broadleaf forest & 581.05 & $\begin{array}{l}470.76 \\
(-19.0 \%)\end{array}$ & $\begin{array}{l}484.52 \\
(-16.6 \%)\end{array}$ & $\begin{array}{l}581.15 \\
(0)\end{array}$ & $\begin{array}{l}575.94 \\
(-0.9 \%)\end{array}$ & $\begin{array}{l}574.13 \\
(-1.2 \%)\end{array}$ \\
\hline Evergreen broadleaf forest & 680.53 & $\begin{array}{l}546.20 \\
(-19.7 \%)\end{array}$ & $\begin{array}{l}565.52 \\
(-16.9 \%)\end{array}$ & $\begin{array}{l}680.87 \\
(0)\end{array}$ & $\begin{array}{l}672.86 \\
(-1.1 \%)\end{array}$ & $\begin{array}{l}670.97 \\
(-1.4 \%)\end{array}$ \\
\hline Mixed broadleaf-conifer forest & 544.31 & $\begin{array}{l}450.56 \\
(-17.2 \%)\end{array}$ & $\begin{array}{l}461.24 \\
(-15.3 \%)\end{array}$ & $\begin{array}{l}544.53 \\
(0)\end{array}$ & $\begin{array}{l}541.69 \\
(-0.5 \%)\end{array}$ & $\begin{array}{l}536.81 \\
(-1.4 \%)\end{array}$ \\
\hline Shrub & 600.12 & $\begin{array}{l}559.96 \\
(-6.7 \%)\end{array}$ & $\begin{array}{l}567.22 \\
(-5.5 \%)\end{array}$ & $\begin{array}{l}601.06 \\
(0.2 \%)\end{array}$ & $\begin{array}{l}597.15 \\
(-0.5 \%)\end{array}$ & $\begin{array}{l}595.65 \\
(-0.7 \%)\end{array}$ \\
\hline Grassland & 517.74 & $\begin{array}{l}480.04 \\
(-7.3 \%)\end{array}$ & $\begin{array}{l}484.70 \\
(-6.4 \%)\end{array}$ & $\begin{array}{l}518.00 \\
(0.1 \%)\end{array}$ & $\begin{array}{l}516.26 \\
(-0.3 \%)\end{array}$ & $\begin{array}{l}514.66 \\
(-0.6 \%)\end{array}$ \\
\hline Cropland & 535.85 & $\begin{array}{l}482.07 \\
(-10.0 \%)\end{array}$ & $\begin{array}{l}488.10 \\
(-8.9 \%)\end{array}$ & $\begin{array}{l}536.81 \\
(0.2 \%)\end{array}$ & $\begin{array}{l}534.26 \\
(-0.3 \%)\end{array}$ & $\begin{array}{l}531.25 \\
(-0.9 \%)\end{array}$ \\
\hline Total & 555.17 & $\begin{array}{l}485.50 \\
(-12.5 \%)\end{array}$ & $\begin{array}{l}494.55 \\
(-10.9 \%)\end{array}$ & $\begin{array}{l}555.78 \\
(0.1 \%)\end{array}$ & $\begin{array}{l}552.92 \\
(-0.4 \%)\end{array}$ & $\begin{array}{l}545.42 \\
(-1.8 \%)\end{array}$ \\
\hline
\end{tabular}

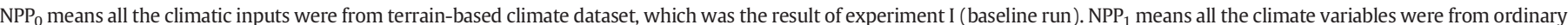

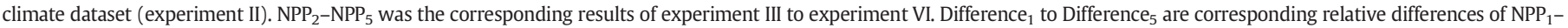
$\mathrm{NPP}_{5}$ in comparison with the $\mathrm{NPP}_{0}$. In addition, the unit of $\mathrm{NPP}_{0}$ to $\mathrm{NPP}_{5}$ is $\mathrm{g} \mathrm{C} \mathrm{m}^{-2} \mathrm{yr}^{-1}$.

discrepancies of mean NPP are steadily decreased afterwards. Slope has simpler impacts on the NPP calculations since NPP discrepancies continually increase with the slope increasing, yet the rates of increment are gradually reduced. As to the aspect, NPP is more likely to be affected in the north and northwest than in the south and southeast.

(4) Primary climate variables contributing to the NPP difference in Wuling mountainous area are temperatures, followed by global solar radiation. Ordinary precipitation and relative humidity almost do not change the model results.

\section{Acknowledgments}

This research was funded by the National Science and Technology Supporting Plan from the Chinese Ministry of Science and Technology (no. 2012BAH33B00). The authors would like to thank Professor Liu Gaohuan, Institute of Geographic Sciences and Natural Resources Research, Chinese Academy of Sciences, for providing some basic input data of the BEPS model. We also sincerely thank Professor Wang Shaoqiang and Dr. Wang Junbang for their help in revising this paper.

\section{References}

Angstrom, A., 1924. Solar and terrestrial radiation. Q. J. R. Meteorol. Soc. 50 (210), $121-126$.

Baldocchi, D.D., Wilson, K.B., Gu, L., 2002. How the environment, canopy structure and canopy physiological functioning influence carbon, water and energy fluxes of a temperate broad-leaved deciduous forest-an assessment with the biophysical model CANOAK. Tree Physiol. 22 (15-16), 1065-1077.

Chen, J.M., Cihlar, J., 1995. Quantifying the effect of canopy architecture on optical measurements of leaf area index using two gap size analysis methods. IEEE Trans. Geosci. Remote Sens. 33 (3), 777-787.

Chen, J.M., Liu, J., Cihlar, J., et al., 1999. Daily canopy photosynthesis model through temporal and spatial scaling for remote sensing applications. Ecol. Model. 124 (2-3) 99-119.

Chen, X.F., Chen, J.M., An, S.Q., et al., 2007. Effects of topography on simulated net primary productivity at landscape scale. J. Environ. Manag. 85 (3), 585-596.

Cramer, W., Field, C.B., 1999. Comparing global models of terrestrial net primary productivity (NPP): introduction. Glob. Chang. Biol. 5 (S1), iii-iv.

Cramer, W., Kicklighter, D.W., Bondeau, A., et al., 1999. Comparing global models of terrestrial net primary productivity (NPP): overview and key results. Glob. Chang. Biol. 5 (S1), 1-15.

Deng, F., Chen, J.M., Plummer, S., et al., 2006. Algorithm for global leaf area index retrieval using satellite imagery. IEEE Trans. Geosci. Remote Sens. 44 (8), 2219-2229.

Farguhar, G.D., Sv, Caemmerer, Berry, J.A., 1980. A biochemical model of photosynthetic $\mathrm{CO}_{2}$ assimilation in leaves of $C_{3}$ species. Planta 149 (1), 78-90.

Feng, X.F., Liu, G.H., Chen, S.P., et al., 2004. Study on process model of net primary productivity of terrestrial ecosystems. J. Nat. Resour. 19 (3), 369-378.
Feng, X.F., Liu, G.H., Chen, J.M., et al., 2007. Net primary productivity of China's terrestrial ecosystems from a process model driven by remote sensing. J. Environ. Manag. 85 (3), 563-573

Grant, R.F., 2004. Modeling topographical effects on net ecosystem productivity of boreal black spruce forests. Tree Physiol. 24 (1), 1-18.

Guo, Z.H., Peng, S.L., Wang, B.S., 2002. Estimating forest biomass in Western Guangdong using Landsat TM data. Acta Ecol. Sin. 22 (11), 1832-1839.

He, Q.H., Xie, Y., 2010. Research on the climatological calculation method of solar radiation in China. J. Nat. Resour. 25 (2), 308-319.

Higuchi, K., Shashkov, A., Chan, D., et al., 2005. Simulation of seasonal and inter-annual variability of gross primary productivity at Takayama with BEPS ecosystem model. Agric. For. Meteorol. 134 (1-4), 143-150.

Huang, W., Zhang, L.P., Furumi, S., et al., 2010. Topographical effects on estimating net primary productivity of green coniferous forest in complex terrain using Landsat data: a case study of Yoshino Mountain, Japan. Int. J. Remote Sens. 31 (11), 2941-2957.

Hutchinson, M.F., 2001. ANUSPLIN Version 4.2 User Guide. Canberra: Center for Resource and Environmental Studies. Australian National University.

Li, X.P., 2013. Estimation of Net Primary Productivity and Analyses of its Spatio-temporal Characteristics in Heihe River Basin. Shaanxi Normal University, Xian, China, pp. 9-19.

Lieth, H., 1972. Computer mapping of forest data. Proceedings of 51st Annual Meeting of Society of American Foresters. Appalachian Section, Carolina, USA, pp. 53-79.

Liu, J., Chen, J.M., Cihlar, J., et al., 1997. A process-based boreal ecosystem productivity simulator using remote sensing inputs. Remote Sens. Environ. 62 (2), $158-175$.

Liu, J., Chen, J.M., Cihlar, J., et al., 1999. Net primary productivity distribution in the BOREAS region from a process model using satellite and surface data. J. Geophys. Res. 104 (D22), 27735-27754.

Liu, J., Chen, J.M., Cihlar, J., et al., 2002. Net primary productivity mapped for Canada at 1-km resolution. Glob. Ecol. Biogeogr. 11 (2), 115-129.

Liu, Y., Liu, R.G., Chen, J.M., 2012. Retrospective retrieval of long-term consistent global leaf area index (1981-2011) from combined AVHRR and MODIS data. J. Geophys. Res. 117, G04003. http://dx.doi.org/10.1029/2012JG002084.

Liu, Y., Huang, B., Yi, C.G., et al., 2013. Simulation by remote sensing and analysis of net primary productivity of vegetation based on topographical correction. Trans. Chin. Soc. Agric. Eng. 29 (13), 130-141.

Luo, T.X., 1996. Patterns of net primary productivity for Chinese major forest types and their mathematical models. Phd Thesis, Beijing: Chinses Academy of Sciences 34-167.

Matsushita, B., Tamura, M., 2002. Integrating remotely sensed data with an ecosystem model to estimate net primary productivity in East Asia. Remote Sens. Environ. 81 (1), 58-66.

Matsushita, B., Xu, M., Chen, J., et al., 2004. Estimation of regional net primary productivity (NPP) using a process-based ecosystem model: how important is the accuracy of climate data? Ecol. Model. 178 (3-4), 371-388.

Nachtergaele, F., Hv, Velthuizen, Verelst, L., et al., 2012. Harmonized World Soil Database User Guide (Version 1.2). FAO, IIASA, ISRIC, ISSCAS, JRC. 8.

Piao, S.L., Fang, J.Y., 2002. Terrestrial net primary production and its spatio-temporal patterns in Qinghai-Xizang Plateau, China during 1982-1999. J. Nat. Resour. 17 (3), 373-380.

Piao, S.L., Tan, K., Nan, H.J., et al., 2012. Impacts of climate and $\mathrm{CO}_{2}$ changes on the vegetation growth and carbon balance of Qinghai-Tibetan grasslands over the past five decades. Glob. Planet. Chang. 98-99, 73-80.

Price, D.T., McKenney, D.W., Nalderc, I.A., et al., 2000. A comparison of two statistical methods for spatial interpolation of Canadian monthly mean climate data. Agric. For. Meteorol. 101 (2-3), 81-94.

Running, S.W., 2012. A measurable planetary boundary for the biosphere. Science 337 (6101), 1458-1459. 
Running, S.W., Coughlan, J.C., 1988. A general model of forest ecosystem processes for regional applications I. Hydrological balance, canopy gas exchange and primary production processes. Ecol. Model. 42 (2), 125-154.

Ryunosuke, T., Takuo, H., Hiroshi, T., 2004. Above- and belowground biomass and net primary production in a cool-temperate deciduous forest in relation to topographical changes in soil nitrogen. For. Ecol. Manag. 193 (3), 297-306.

Sun, Q.L., Feng, X.F., et al., 2014. Topographic effects of climate dataset and their impacts on the estimation of regional net primary productivity. In: Gong, P. (Ed.), Land Surface Remote Sensing II. SPIE Asia-Pacific Remote Sensing Proceedings No. 9260, Beijing, China.

Tian, H., Chen, G., Liu, M., et al., 2010. Model estimates of net primary productivity, evapotranspiration, and water use efficiency in the terrestrial ecosystems of the southern United States during 1895-2007. For. Ecol. Manag. 259 (2010), 1311-1327.

Wang, J.B., 2004. Chinese terrestrial net ecosystem productive model applied remote sensing data. PhD Thesis. Zhejiang University, Hangzhou, China, p. 91.
Weng, D.M., 1997. Radiation Climate in China. China Meteorological Press, Beijing pp. 100-146.

Xu, C., Liu, M., An, S., et al., 2007. Assessing the impact of urbanization on regional net primary productivity in Jiangyin County, China. J. Environ. Manag. 85 (3), 597-606.

Zheng, L.Y., 2006. Study on Dynamic Change of NPP and Grassland Change in Northern Tibet based on Remote Sensing and Biological Processes Model BEPS. Chinese Academy of Meteorological Sciences, Beijing, China, pp. 48-49.

Zhou, G.S., Wang, Y.H., 2003. Global Ecology. China Meteorological Press, Beijing, p. 189. Zhou, G.S., Zhang, X.S., 1995. A natural vegetation NPP model. Acta Phytoecol. Sin. 19 (3), 193-200.

Zhou, Y., Zhu, Q., Chen, J.M., et al., 2007. Observation and simulation of net primary productivity in Qilian Mountain, western China. J. Environ. Manag. 85 (3), 574-584.

Zhu, W.Q., Chen, Y.H., Xu, D., et al., 2005. Advances in terrestrial net primary productivity (NPP) estimation models. Chin. J. Ecol. 24 (3), 296-300. 